\title{
Evaluation of Blood Flow in Carotid Artery Stenosis Using B-Flow Sonography
}

\author{
Takeshi MIKAMI, Akira TAKAHASHI, and Kiyohiro HOUKIN* \\ Department of Neurosurgery, Sunagawa City Medical Center, Sunagawa, Hokkaido; \\ *Department of Neurosurgery, Sapporo Medical University, Sapporo, Hokkaido
}

\begin{abstract}
B-flow ultrasonography can directly visualize blood streams by reflecting the intravascular red blood cells, and so can detect turbulent flow in vessels. B-flow sonography was used to evaluate flow abnormalities in patients with cervical carotid artery stenosis, and to investigate the mechanism of large embolus formation that may cause distal arterial occlusion. Twenty-two patients with $\geq 60 \%$ stenosis of the cervical carotid artery excluding cardiovascular embolism were examined by B-flow and color Doppler sonography. Two patients had distal embolism as revealed by digital subtraction angiography, 16 patients had lacunar infarction, and four patients had transient ischemic attacks. B-flow sonography demonstrated reverse flow at the poststenotic site in patients with $\geq 70 \%$ stenosis. Increased echogenicity at the site of the stenosis was seen in patients with at least $80 \%$ stenosis. Prestenotic reverse flow was seen in nine patients with $\geq 85 \%$ stenosis. The two patients with distal embolism had decreased echogenicity and flow velocity, and diastolic flow was absent. B-flow sonography could detect various turbulent flow patterns and changes in echogenicity associated with cervical carotid artery stenosis. Prestenotic reverse flow and decreased flow velocity may be potential causes of distal embolism. B-flow sonography is a useful method for the evaluation of flow abnormality in patients with carotid artery stenosis.
\end{abstract}

Key words: B-flow, sonography, carotid artery stenosis

\section{Introduction}

Most symptomatic patients with severe carotid artery stenosis benefit from endarterectomy. ${ }^{7,17)}$ Endarterectomy is also the method of choice for the treatment of asymptomatic patients with severe carotid artery stenosis. ${ }^{8)}$ Therefore, screening for carotid artery stenosis is of considerable clinical importance. ${ }^{1)}$

Many modalities can be used to evaluate the carotid artery including magnetic resonance angiography, computed tomography (CT) angiography, and digital subtraction angiography (DSA). A number of surgeons rely on sonography as a noninvasive, cost-effective modality to assess carotid artery disease. ${ }^{2)}$ Color Doppler flow imaging and power Doppler imaging enable the evaluation of blood flow, but both have some limitations including angle-dependency, aliasing, blooming, and noises from cardiac and respiratory motion. ${ }^{12,16,24,25)}$

The recent development of B-flow technology now allows gray scale sonography to visually display blood flow. ${ }^{4,10,20,28)}$ B-flow imaging is produced by echoes from intravascular red blood cells using digitally encoded ultrasound technology, including coded excitation techniques. ${ }^{10)}$ Consequently, this technique makes it possible to visualize real-time blood stream and complex flow patterns in relation to stationary tissue. B-flow imaging has wideband resolution and a high frame rate, and provides high spatial resolution, so can be used to evaluate and measure carotid artery stenosis as effectively as DSA. ${ }^{28)}$

The present study evaluated flow abnormalities in the stenotic portion and pre- and poststenotic portions of the cervical carotid artery in patients with cervical carotid artery stenosis using B-flow sonography, and investigated the possible mechan-

Received December 17, 2002; Accepted May 21, 2003

Author's present address: T. Mikami, M.D., Department of Neurosurgery, Sapporo Medical University, Sapporo, Hokkaido, Japan. 
Table 1 Summary of clinical, B-flow sonography, and digital subtraction angiography characteristics

\begin{tabular}{|c|c|c|c|c|c|c|c|c|}
\hline $\begin{array}{l}\text { Case } \\
\text { No. }\end{array}$ & $\begin{array}{l}\text { Age (yrs)/ } \\
\text { Sex }\end{array}$ & $\begin{array}{l}\text { Carotid artery } \\
\text { stenosis* }\end{array}$ & $\begin{array}{c}\text { ICA } \\
\text { reverse } \\
\text { flow }\end{array}$ & $\begin{array}{l}\text { Increased } \\
\text { echogenicity }\end{array}$ & $\begin{array}{c}\text { CCA } \\
\text { reverse } \\
\text { flow }\end{array}$ & $\begin{array}{l}\text { Hypo- } \\
\text { PSV }\end{array}$ & $\begin{array}{l}\text { Distal } \\
\text { thrombus }\end{array}$ & $\begin{array}{c}\text { Plaque } \\
\text { morphology }\end{array}$ \\
\hline 1 & $69 / \mathrm{M}$ & 60 & - & - & - & - & - & echogenic \\
\hline 2 & $66 / F$ & 60 & - & - & - & - & - & mixed \\
\hline 3 & $78 / F$ & 60 & - & - & - & - & - & echogenic \\
\hline 4 & $65 / \mathrm{M}$ & 60 & - & - & - & - & - & echogenic \\
\hline 5 & $78 / \mathrm{M}$ & 65 & - & - & - & - & - & echogenic \\
\hline 6 & $68 / \mathrm{M}$ & 65 & - & - & - & - & - & echogenic \\
\hline 7 & $77 / \mathrm{M}$ & 70 & + & - & - & - & - & echogenic \\
\hline 8 & $64 / F$ & 70 & + & - & - & - & - & calcification \\
\hline 9 & $76 / \mathrm{M}$ & 70 & + & - & - & - & - & echogenic \\
\hline 10 & $73 / \mathrm{F}$ & 80 & + & + & - & - & - & calcification \\
\hline 11 & $71 / \mathrm{M}$ & 80 & + & + & - & - & - & echogenic \\
\hline 12 & $75 / \mathrm{M}$ & 85 & + & - & - & - & - & echogenic \\
\hline 13 & $72 / \mathrm{M}$ & 85 & + & + & + & - & - & echogenic \\
\hline 14 & $68 / \mathrm{M}$ & 85 & + & + & - & - & - & echolucent \\
\hline 15 & $79 / \mathrm{M}$ & 85 & + & + & + & - & - & echogenic \\
\hline 16 & $71 / \mathrm{M}$ & 85 & + & + & + & - & - & echogenic \\
\hline 17 & $82 / \mathrm{M}$ & 85 & + & + & + & - & - & echogenic \\
\hline 18 & $66 / \mathrm{M}$ & 90 & + & + & + & - & - & echogenic \\
\hline 19 & $68 / \mathrm{M}$ & 90 & + & + & + & - & - & echogenic \\
\hline 20 & $66 / \mathrm{M}$ & 95 & + & + & + & - & - & mixed \\
\hline 21 & $72 / \mathrm{M}$ & 95 & + & + & + & + & + & mixed \\
\hline 22 & $71 / \mathrm{M}$ & 95 & + & + & + & + & + & echogenic \\
\hline
\end{tabular}

${ }^{*}$ According to the North American Symptomatic Carotid Endarterectomy Trial criteria. ${ }^{17)}$ CCA: common carotid artery, hypo-PSV: peak systolic velocity $<25 \mathrm{~cm} / \mathrm{sec}$, ICA: internal carotid artery.

isms for large embolus formation that may cause distal arterial occlusion.

\section{Methods}

\section{Subjects}

Twenty-two consecutive patients, 18 men and four women aged 64 to 82 years (mean $71.6 \pm 5.1$ years), with symptomatic cervical carotid artery stenosis underwent carotid artery B-flow sonography and DSA for suspected cervical carotid artery disease between May 2001 and April 2002. DSA and B-flow sonography were performed within a maximum of 5 days in patients with $\geq 60 \%$ cervical carotid artery stenosis. The primary cause of stroke was cortical infarction due to distal embolism as revealed by DSA in two patients, lacunar infarction in 16 patients, and transient ischemic attacks (TIAs) in four patients.

\section{B-flow sonography}

All examinations were performed by the same experienced sonographers and all data analysis was performed by another investigator. Sonography used a LOGIQ 700 unit (General Electric, Yokogawa
Medical Systems, Tokyo) equipped with a wide bandwidth (5-10 MHz) linear-array transducer. Bflow sonography was performed at $10 \mathrm{MHz}$ with Bflow capability at the level of the common carotid artery to the cervical internal carotid artery. B-flow gain was not fixed and was adjusted to allow good visualization of the blood stream. The depth of visualization of the carotid artery was within 2.0 to $7.5 \mathrm{~cm}$. Blood flow was visualized as pixel brightness or intensity on the B-flow images according to blood echo strength and blood flow velocity. When consistent Doppler signals were obtained, B-mode flow was used to guide the placement of a pulsed Doppler gate and tracings of the arterial signal were appropriately recorded using a sample volume of $1 \mathrm{~mm}^{3}$, and angle-corrected spectral analysis was performed to determine the peak systolic velocity.

Hemodynamic blood flow abnormalities were analyzed, especially turbulent flow in the portion of the vessel including the stenotic and pre- and poststenotic portions using B-flow and color Doppler flow imaging. The sonographic criteria were: presence or absence (obliteration) of reverse flow in the prestenotic portion, flow velocity of the prestenotic portion, echogenicity in the stenotic 

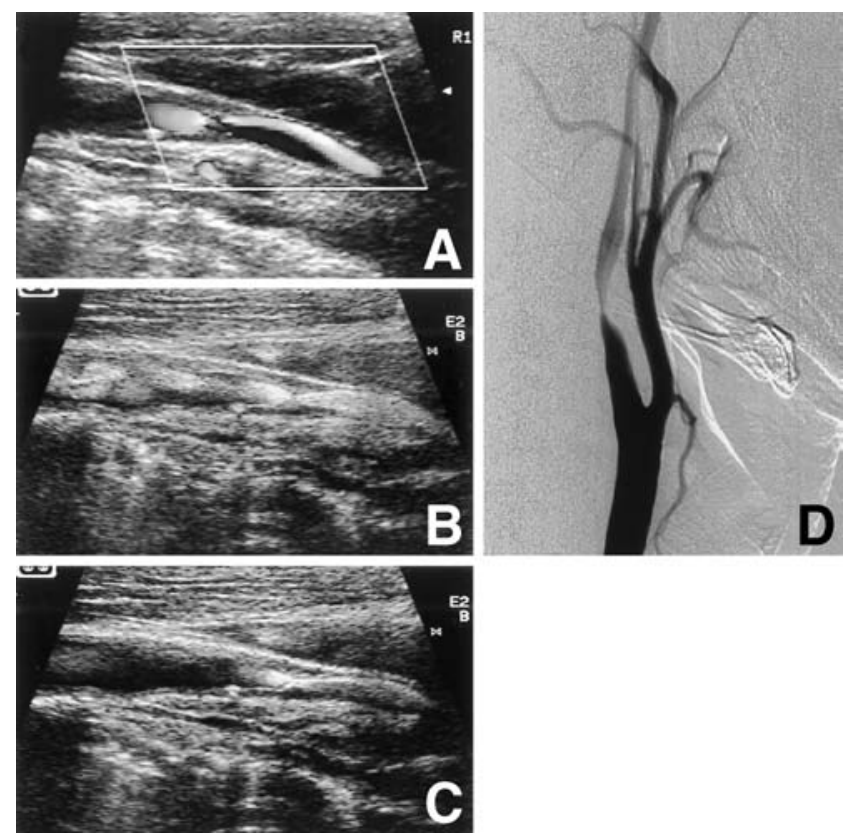

Fig. 1 Case 18. A 66-year-old man with right cervical carotid artery stenosis. A: Color Doppler flow image showing echolucent plaque and flow image superimposed on the vessel wall. B: B-flow image in the systolic phase showing reverse flow in the pre- and poststenotic regions and high echogenicity at the stenotic region. C: B-flow image in the diastolic phase showing jet flow at the poststenotic region. D: Right carotid artery angiogram, lateral view, showing internal carotid artery stenosis.

portion, presence or absence of reverse flow in the poststenotic potion, and flow velocity of the poststenotic portion.

\section{DSA technique}

Selective DSA of the carotid and cerebral arteries was performed via the brachial artery, starting routinely with selective injection of contrast material (Optiley; Yamanouchi, Tokyo; 5-8 ml) into the bilateral common carotid and subclavian arteries and at least one vertebral artery. DSA was performed routinely using anteroposterior and lateral projections with a $33-\mathrm{cm}$ field of view and a $1024 \times$ 1024 matrix. The spatial resolution was $0.32 \times$ $0.32 \mathrm{~mm}$. If a bifurcation was not adequately visualized, DSA was performed using an oblique projection.

Grading of stenosis used the North American Symptomatic Carotid Endarterectomy Trial criteria. ${ }^{17)}$ The image that demonstrated the most severe stenosis was used. The diameter of the most severe
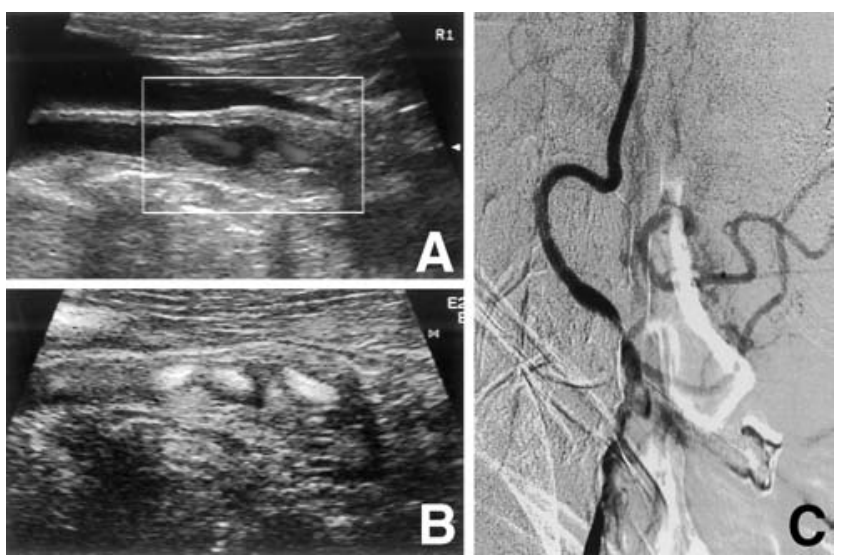

Fig. 2 Case 22. A 71-year-old man with right cervical carotid artery stenosis. A: Color Doppler flow image showing mixed plaque with thrombus in the prestenotic region. Flow image shown in color. B: B-flow image in the systolic phase showing turbulent flow in the prestenotic region because of thrombus and the stenotic region. C: Right carotid artery angiogram, lateral view, showing internal carotid artery stenosis, external carotid artery occlusion, and thrombus in the common carotid artery.

stenosis was divided by the diameter of the distal cervical internal carotid artery beyond the stenosis to calculate the percentage stenosis.

\section{Statistical analysis}

Statistical analysis was used for all comparisons between sonographic criteria for cervical stenosis and distal embolus detected by DSA. One-way analysis of variance was used to compare groups. Fisher's exact probability test was used to evaluate the statistical difference between the groups. The level of statistical significance was considered to be $\mathrm{p}<0.01$.

\section{Results}

Blood flow and plaque morphology could be evaluated simultaneously in all cases. B-mode flow showed all flow patterns clearly without blooming. In particular, the flow patterns around calcification plaques were more clearly visualized than with color flow imaging. Flow patterns at the cervical stenosis of the 22 vessels are indicated in Table 1 . Reverse flow at the poststenotic region was seen in 16 vessels with at least $70 \%$ carotid artery stenosis (Fig. 1). Increased echogenicity at the site of stenosis was seen in 12 vessels with at least $80 \%$ carotid artery stenosis. Reverse flow at the prestenotic region was 
visualized as moyamoya echo in nine vessels with at least $85 \%$ carotid artery stenosis. Decreased echogenicity due to a decline in flow velocity was seen in two vessels at the prestenotic site (Fig. 2). Peak systolic velocity in these two vessels was less than $25 \mathrm{~cm} / \mathrm{sec}$, and diastolic flow was absent. These vessels had severe stenosis of at least $95 \%$ associated with stenosis or occlusion of the external carotid artery.

DSA showed occlusion of the distal internal carotid artery and middle cerebral artery in two patients. Cardioechography and Holter electrocardiography found no abnormal findings, and the embolic source considered to depend on cervical carotid artery stenosis in two of these cases. A significant inverse correlation was found between the decline of the flow velocity in the common carotid artery and distal embolism revealed by DSA $(p=0.0043)$. No correlation was found between reverse flow at the poststenotic region, increased echogenicity at the site of stenosis, reverse flow at the prestenotic region, and sonographic plaque morphology.

\section{Discussion}

In this study, B-flow sonography of the carotid arteries was applied to evaluate the complex blood flow patterns present in carotid artery disease. The normal flow patterns observed in the inferior bulb are associated with wall shear stress ${ }^{3,9)}$ and flow separation, ${ }^{15)}$ which are important factors in the pathogenesis of atherosclerotic plaques, which most often form at this site in the carotid artery. Laminar flow theory, an important concept in hemodynamics, ${ }^{11,13)}$ suggests that blood flow in the arterial vessels is faster in the inner layers of the lumen and slower in the outer layers of the lumen, because of the viscosity of the blood. In the carotid bulb, flow velocity decreases and intra-arterial pressure increases according to Bernoulli's law, because of the widening of the lumen. Slower flow laminae at the outer layers of lumen are pushed back and separated from the wall (flow separation), so local turbulence and recirculation occur. In laminar flow, shear stresses increase in proportion to the velocity gradient according to Poiseuille's law, because of the difference of flow velocity. Shear stress is increased at the arterial wall (wall shear stress), resulting in slower flow in the flow separation. The consequent stasis of blood flow causes platelet aggregation and transport of lipids.

A longitudinal study of carotid atheroma with sonography has shown that hypoechoic and severely stenosed plaques are associated with a higher inci- dence of stroke. ${ }^{14,19,23,26)}$ In addition, ulcerated plaques on sonography are associated with neurovascular symptoms, ${ }^{5,6,21)}$ whereas hyperechoic and smooth-surfaced plaques are associated with asymptomatic status. The plaque density on CT angiography is also an important indicator for the prediction of plaque stability. ${ }^{18)}$

The present study was conducted to identify the hemodynamic factors leading to formation of thrombus. The severe constriction in cervical stenosis causes reverse flow and increased shear stress, which is proportional to the degree of stenosis and becomes maximal just before the point of maximum constriction. The mechanical damage promotes arterial endothelium damage at the point of stenosis, enhancing platelet aggregation and transport of lipids. Measurement of the local velocity can predict the formation of a thrombus. The lower incidence of TIAs in patients with $50-69 \%$ and $90-99 \%$ internal carotid artery stenosis may be explained by the hypothesis that the plaque is more stable in the former case, whereas the lower flow velocity at the poststenotic site in the latter fails to dislodge embolus from the plaque surface, so no distal migration of the embolus occurs. ${ }^{22)}$ A low-flow cerebral protection hypothesis was recently proposed to explain the low risk of stroke in patients with almost complete carotid artery occlusion. ${ }^{27)}$ However, the flow velocities near the wall and orifice of the stenosis are quite low, so the lower flow velocity in the common carotid artery (peak systolic velocity $<25 \mathrm{~cm} / \mathrm{sec}$ ) may increase the risk of large embolus formation. Our results suggest that half of patients with $70-89 \%$ internal carotid artery stenosis have had prior stroke or TIAs. Decreased flow velocity, in addition to reverse flow, at the prestenotic site is more likely to cause the formation of large embolus and distal arterial occlusion. The lower flow velocity and reverse flow may cause blood flow stasis, which is one of the causes of platelet adhesion and aggregation of red blood cells at the rupture site of the intima that becomes the surface of plaque. The decrease in flow velocity is associated with formation of large thrombi and may cause distal embolism of the large vessels.

\section{References}

1) Bogousslavsky J, Kaste M, Skyhoj Olsen T, Hacke W, Orgogozo JM: Risk factors and stroke prevention. European Stroke Initiative (EUSI). Cerebrovasc Dis 10 (Suppl 3): 12-21, 2000

2) Brant-Zawadzki M, Heiserman JE: The roles of MR angiography, CT angiography, and sonography in vascular imaging of the head and neck. AJNR Am J Neuroradiol 18: 1820-1825, 1997 
3) Caro CG, Fitz-Gerald JM, Schroter RC: Atheroma and arterial wall shear. Observation, correlation and proposal of a shear dependent mass transfer mechanism for atherogenesis. Proc R Soc Lond B Biol Sci 177: 109-159, 1971

4) Deane C: Extended field-of-view and B-flow ultrasound: fashion or future? Ultrasound Obstet Gynecol 15: 96-97, 2000

5) Dixon S, Pais SO, Raviola C, Gomes A, Machleder HI, Baker JD, Busuttil RW, Barker WF, Moore WS: Natural history of nonstenotic, asymptomatic ulcerative lesions of the carotid artery. A further analysis. Arch Surg 117: 1493-1498, 1982

6) Eliasziw M, Streifler JY, Fox AJ, Hachinski VC, Ferguson GG, Barnett HJ: Significance of plaque ulceration in symptomatic patients with high-grade carotid stenosis. North American Symptomatic Carotid Endarterectomy Trial. Stroke 25: 304-308, 1994

7) European Carotid Surgery Trialists' Collaborative Group: MRC European Carotid Surgery Trial: Interim results for symptomatic patients with severe (70-99\%) or with mild (0-29\%) carotid stenosis. Lancet 337: 1235-1243, 1991

8) Executive Committee for the Asymptomatic Carotid Atherosclerosis Study: Endarterectomy for asymptomatic carotid artery stenosis. JAMA 273: 1421-1428, 1995

9) Fry DL: Acute vascular endothelial changes associated with increased blood velocity gradients. Circ Res 22: 165-197, 1968

10) Furuse J, Maru Y, Mera K, Sumi H, Yoshino M, Yokoyama Y, Hashimoto H, Ejiri A: Visualization of blood flow in hepatic vessels and hepatocellular carcinoma using B-flow sonography. J Clin Ultrasound 29: 1-6, 2001

11) Grady PA: Pathophysiology of extracranial cerebral arterial stenosis - a critical review. Stroke 15: 224-236, 1984

12) Griewing B, Morgenstern C, Driesner F, Kallwellis G, Walker ML, Kessler C: Cerebrovascular disease assessed by color-flow and power Doppler ultrasonography. Comparison with digital subtraction angiography in internal carotid artery stenosis. Stroke 27: 95-100, 1996

13) Imbesi SG, Kerber CW: Why do ulcerated atherosclerotic carotid artery plaques embolize? A flow dynamics study. AJNR Am J Neuroradiol 19: 761-766, 1998

14) Liapis CD, Kakisis JD, Kostakis AG: Carotid stenosis: factors affecting symptomatology. Stroke 32: 2782-2786, 2001

15) Motomiya M, Karino T: Flow patterns in the human carotid artery bifurcation. Stroke 15: 50-56, 1984

16) Muller M, Ciccotti P, Reiche W, Hagen T: Comparison of color-flow Doppler scanning, power Doppler scanning, and frequency shift for assessment of carotid artery stenosis. J Vasc Surg 34: 1090-1095, 2001

17) North American Symptomatic Carotid Endarterec- tomy Trial Collaborators: Beneficial effect of carotid endarterectomy in symptomatic patients with highgrade carotid stenosis. N Engl J Med 325: 445-453, 1991

18) Oliver TB, Lammie GA, Wright AR, Wardlaw J, Patel SG, Peek R, Ruckley CV, Collie DA: Atherosclerotic plaque at the carotid bifurcation: CT angiographic appearance with histopathologic correlation. AJNR Am J Neuroradiol 20: 897-901, 1999

19) Polak JF, Shemanski L, O’Leary DH, Lefkowitz D, Price TR, Savage PJ, Brant WE, Reid C: Hypoechoic plaque at US of the carotid artery: an independent risk factor for incident stroke in adults aged 65 years or older. Cardiovascular Health Study. Radiology 208: 649-654, 1998

20) Pooh RK: New application of B-flow sono-angiography in perinatology. Ultrasound Obstet Gynecol 15: 163, 2000

21) Rothwell PM, Gibson R, Warlow CP: Interrelation between plaque surface morphology and degree of stenosis on carotid angiograms and the risk of ischemic stroke in patients with symptomatic carotid stenosis. On behalf of the European Carotid Surgery Trialists' Collaborative Group. Stroke 31: 615-621, 2000

22) Rothwell PM, Warlow CP: Low risk of ischemic stroke in patients with reduced internal carotid artery lumen diameter distal to severe symptomatic carotid stenosis: cerebral protection due to low poststenotic flow? On behalf of the European Carotid Surgery Trialists' Collaborative Group. Stroke 31: 622-630, 2000

23) Steinke W, Hennerici M, Rautenberg W, Mohr JP: Symptomatic and asymptomatic high-grade carotid stenoses in Doppler color-flow imaging. Neurology 42: 131-138, 1992

24) Steinke W, Meairs S, Ries S, Hennerici M: Sonographic assessment of carotid artery stenosis. Comparison of power Doppler imaging and color Doppler flow imaging. Stroke 27: 91-94, 1996

25) Steinke W, Ries S, Artemis N, Schwartz A, Hennerici M: Power Doppler imaging of carotid artery stenosis. Comparison with color Doppler flow imaging and angiography. Stroke 28: 1981-1987, 1997

26) Tegos TJ, Sohail M, Sabetai MM, Robless P, Akbar N, Pare G, Stansby G, Nicolaides AN: Echomorphologic and histopathologic characteristics of unstable carotid plaques. AJNR Am J Neuroradiol 21: 1937-1944, 2000

27) Tsiskaridze A, Devuyst G, de Freitas GR, van Melle G, Bogousslavsky J: Stroke with internal carotid artery stenosis. Arch Neurol 58: 605-609, 2001

28) Umemura A, Yamada K: B-mode flow imaging of the carotid artery. Stroke 32: 2055-2057, 2001

Address reprint requests to: T. Mikami, M.D., Department of Neurosurgery, Sapporo Medical University, South-1 West-16, Chuo-ku, Sapporo, Hokkaido 060-8543, Japan.

e-mail: tmikami@sapmed.ac.jp 


\section{Commentary}

The authors have carefully analyzed 22 consecutive patients with cervical carotid artery stenosis utilizing B-flow sonography, color Doppler sonography and digital subtraction angiography to correlate the findings among these imaging modalities. As pointed out by the authors, many modalities have been used to screen and evaluate patients suspected of having hemodynamically significant stenosis of the cervical carotid arteries. Each of these imaging modalities has advantages and disadvantages. Although the gold standard for evaluating carotid stenosis remains digital subtraction angiography, this invasive test is associated with some risk, discomfort and expense. The authors have demonstrated the utility of B-flow technology to visually display blood flow. The authors have demonstrated that this technology not only images carotid stenosis, but allows one to investigate flow patterns that may lend insight into the mechanisms of turbulent blood flow and subsequent emboli- zation as a cause for cerebral ischemia. As with all sonographic imaging, the quality of individual studies is very operator-dependent. If performed by an inexperienced technician, false-positive and false-negative examinations may be problematic. Over the past several years we have relied more heavily on MR angiography and, more recently, CT angiography in the evaluation of patients with cerebral ischemia. CT angiography not only provides outstanding image of the cervical carotid artery, but will also demonstrate the relationship of the carotid bifurcation to important anatomical landmarks such as the cervical spine and will provide excellent images of the intracranial circulation as well. The authors are to be congratulated for their thorough investigation of $B$ flow sonography, which clearly has a role in the evaluation of carotid stenosis.

Daniel L. BARROW, M.D. Department of Neurosurgery

The Emory Clinic Atlanta, Georgia, U.S.A. 